rh 19 Revue d'histoire du XIXe siècle

Société d'histoire de la révolution de 1848 et des

révolutions du XIXe siècle

$48 \mid 2014$

Usages du droit

\title{
Lettres de la Félibresse rouge Lydie Wilson de Ricard (1850-1880), édition critique établie par Rose Blin- Mioch
}

Montpellier, Presses universitaires de la Méditerranée, 2013, 334 p.

ISBN : 978-2-36781-019-5. 24 euros.

\section{Raymond Huard}

\section{(2) OpenEdition}

Journals

Édition électronique

URL : http://journals.openedition.org/rh19/4691

DOI : 10.4000/rh19.4691

ISSN : $1777-5329$

Éditeur

La Société de 1848

Édition imprimée

Date de publication : 1 juin 2014

Pagination : 196-197

ISSN : 1265-1354

\section{Référence électronique}

Raymond Huard, «Lettres de la Félibresse rouge Lydie Wilson de Ricard (1850-1880), édition critique établie par Rose Blin-Mioch », Revue d'histoire du XIXe siècle [En ligne], 48 | 2014, mis en ligne le 18 septembre 2014, consulté le 22 septembre 2020. URL : http://journals.openedition.org/rh19/4691 DOI : https://doi.org/10.4000/rh19.4691

Ce document a été généré automatiquement le 22 septembre 2020.

Tous droits réservés 


\section{Lettres de la Félibresse rouge Lydie Wilson de Ricard (1850-1880), édition critique établie par Rose Blin-Mioch}

Montpellier, Presses universitaires de la Méditerranée, 2013, 334 p. ISBN : 978-2-36781-019-5. 24 euros.

\section{Raymond Huard}

\section{RÉFÉRENCE}

Lettres de la Félibresse rouge Lydie Wilson de Ricard (1850-1880), édition critique établie par Rose Blin-Mioch, Montpellier, Presses universitaires de la Méditerranée, 2013, 334 p. ISBN : 978-2-36781-019-5. 24 euros.

1 Voici un ensemble de correspondances originales, très soigneusement présentées et éditées par Rose Blin-Mioch et qui concernent le Félibrige rouge, constitué autour de Louis-Xavier de Ricard à partir de 1876. Au total soixante-dix lettres parfois très développées dont le cœur est fourni par celles de Lydie Wilson de Ricard au félibre Auguste Fourès, de Castelnaudary (34 lettres) et par les réponses de ce dernier (14 missives); les autres correspondances (14) étant échangées entre Louis-Xavier de Ricard et Auguste Fourès ${ }^{1}$.

Louis-Xavier de Ricard, après avoir participé à la Commune de Paris, s'est exilé en Suisse. Revenu en France, il épouse, en août 1873, Lydie Wilson, née en 1850 à Paris, fille ânée d'un commerçant d'origine écossaise et d'une mère d'origine flamande. Celle-ci a reçu, tant en France qu'en Écosse, une éducation variée et poussée. Au début de 1874, les Ricard s'installent à Montpellier. Par opposition au félibrige blanc et provençal, le félibrige languedocien animé par Ricard est " rouge », ardemment républicain et même socialisant. Il se manifestera par l'édition d'un almanach annuel en occitan et français et autres langues romanes, la Lauseta ${ }^{2}$, la publication de l'ouvrage de Ricard, Le Fédéralisme ${ }^{3}$, en janvier 1877 et diverses autres publications. C'est au printemps 1876 
que les Ricard font connaissance d'Auguste Fourès, commerçant à Castelnaudary, mais aussi poète languedocien et républicain avancé. À partir de quoi commence entre Lydie et Fourès et éventuellement entre Louis et ce dernier, une correspondance suivie et fraternelle. Alors que les lettres de Louis-Xavier concernent surtout le sort du félibrige, celles de Lydie sont beaucoup plus intimes. Elle a manifestement trouvé en ce jeune homme de vingt-huit ans un confident (il sera bientôt son "parrain" et elle sa " filleule »). Fourès est en outre tombé amoureux de Jeanne, la sœur cadette de Lydie, et celle-ci sert d'intermédiaire entre les tourtereaux. Cette correspondance s'arrête du reste avec la mort de Jeanne, tuberculeuse, en novembre 1877. Lydie décèdera le 17 septembre 1880 de la même maladie, la maladie du siècle, dont le nom, par une sorte de tabou, n'est jamais prononcé dans les lettres.

3 Celles-ci sont très vivantes, écrites avec spontanéité et fraîcheur, surtout de la part de Lydie et elles concernent à peu près tous les aspects de la vie des Ricard. Et d'abord leur installation en Languedoc, dont la nature a séduit Lydie, qui élève même divers animaux. Mais on y voit aussi vivre le couple Ricard qui traverse une crise à l'époque (Lydie songe un instant à s'en aller). Si Louis-Xavier a de bonnes idées concernant l'émancipation de la femme, il ne les applique pas - semble-t-il - dans son ménage. Sa femme qui l'assiste dans son travail, le juge velléitaire, le voit comme un "tyran", souffre d'être considérée comme " un caprice, une petite chose amusante». Sans être vraiment pauvres, les Ricard ne sont pas riches ; ils s'endettent parfois pour financer leurs activités, leurs voyages à Paris. Lydie s'est passionnée pour le languedocien, qu'elle apprend patiemment, mais difficilement, écrit même quelque poèmes dans cette langue en sollicitant les conseils de Fourès. Elle commente les réunions des félibres, critique sévèrement certains d'entre eux (Léontine Goirand, Louis Roumieux). Elle active la diffusion de l'ouvrage de son mari, Le Fédéralisme, dont les comptes rendus de presse sont peu nombreux, malgré les efforts de Fourès. Lydie s'intéresse aussi à la politique, notamment lors de la crise du 16 mai 1877, et craint à cette époque, contrairement à la plupart des républicains, un retour de Thiers au pouvoir (car les souvenirs de la Commune ne sont pas éteints). Les Ricard sont volontiers anticléricaux, anti-jésuites.

4 Une partie importante de la correspondance est consacrée au sort de Jeanne. Celle-ci, personnalité un peu passive et qui s'adonne à la peinture, est tombée amoureuse de Fourès, amour réciproque. Mais les obstacles entre les deux jeunes gens sont immenses: Fourès habite loin de Montpellier, il est peu aisé, dominé par une mère autoritaire et "victime des prêtres ». En outre les parents de Jeanne préfèreraient un gendre vraiment fortuné. Les amoureux ne se voient que très rarement. De là, plaintes et douleurs! Lydie tarabuste Fourès pour qu'il s'installe à Montpellier. La mort de Jeanne est un véritable crève-cœur pour sa sœur : «nul n'aima et n'aime mon adorée pauvre Jeanne comme moi ». Quant à Ricard, il est surtout préoccupé par ses travaux en cours, la sortie du Fédéralisme, la parution de La Lauseta, la rédaction d'une Histoire populaire du Languedoc, ses rapports avec les autres félibres «cagots " (bigots et hypocrites) et les revues (la Revue des langues romanes), la création de la Cigale, regroupement de méridionaux à Paris. Lui non plus n'est pas tendre pour ses confrères, notamment pour Arnavielle, « une espèce de vilain petit Tartuffe ».

Ces lettres sont donc une introduction vivante à un milieu restreint certes, mais très original, et dans une époque décisive. Rose Blin-Mioch en montre aussi la portée plus générale en en confrontant les acquis à des sujets plus vastes, la situation de l'écriture 
des femmes à l'époque, l'état de l'occitan dans les lettres, et aussi les rapports hommesfemmes dans la France du XIX ${ }^{e}$ siècle.

\section{NOTES}

1. Auxquelles viennent encore s'ajouter quelques lettres de Lydie à sa famille (7) et une lettre à Mistral, un peu postérieure (1879 ou 1880).

2. "L'Alouette ». C'est le nom du mas des Ricard à Montpellier.

3. Louis-Xavier de Ricard, Le Fédéralisme, Paris, Sandoz et Fischbacher, 1877. 